\title{
Biocomposites of Epoxidized Natural Rubber/Poly(Lactic Acid) Modified with Natural Substances: Influence of Biomolecules on the Aging Properties (Part II)
}

\author{
Anna Masek * (D) and Stefan Cichosz (D) \\ Institute of Polymer and Dye Technology, Faculty of Chemistry, Lodz University of Technology, \\ Stefanowskiego 12/16, 90-924 Lodz, Poland; stefan.cichosz@dokt.p.lodz.pl \\ * Correspondence: anna.masek@p.lodz.pl
}

check for

updates

Citation: Masek, A.; Cichosz, S. Biocomposites of Epoxidized Natural Rubber/Poly(Lactic Acid) Modified with Natural Substances: Influence of Biomolecules on the Aging Properties (Part II). Polymers 2021, 13, 1677. https://doi.org/10.3390/ polym13111677

Academic Editors:

Beata Podkościelna and

Andrzej Puszka

Received: 12 May 2021

Accepted: 19 May 2021

Published: 21 May 2021

Publisher's Note: MDPI stays neutral with regard to jurisdictional claims in published maps and institutional affiliations.

Copyright: (c) 2021 by the authors. Licensee MDPI, Basel, Switzerland. This article is an open access article distributed under the terms and conditions of the Creative Commons Attribution (CC BY) license (https:// creativecommons.org/licenses/by/ $4.0 /)$.

\begin{abstract}
The aim of this study is to present the possible influence of natural substances on the aging properties of epoxidized natural rubber (ENR) and poly(lactic acid) (PLA) eco-friendly elastic blends. Therefore, the ENR/PLA blends were filled with natural pro-health substances of potentially antioxidative behavior, namely, $\delta$-tocopherol (vitamin E), curcumin, $\beta$-carotene and quercetin. In this way, the material biodeterioration potential was maintained and the material's lifespan was prolonged while subjected to increased temperatures or high-energy UVA irradiation (340 nm). The investigation of the samples' properties indicated that curcumin and quercetin are the most promising natural additives that may contribute to the delay of ENR/PLA degradation under the above-mentioned conditions. The efficiency of the proposed new natural anti-aging additives was proven with static mechanical analysis, color change investigation, as well as mass loss during a certain aging. The aging coefficient, which compares the mechanical properties before and after the aging process, indicated that the ENR/PLA performance after $200 \mathrm{~h}$ of accelerated aging might decrease only by approximately $30 \%$ with the blend loaded with quercetin. This finding paves new opportunities for bio-based and green anti-aging systems employed in polymer technology.
\end{abstract}

Keywords: poly(lactic acid); epoxidized natural rubber; polymer blend; natural additives; antioxidant

\section{Introduction}

Hybrid plastic materials are referred as blends of two types of polymers: bio- and petro-based. Due to substituting a part of the petro-based resin with polymers and additives from renewable resources, they are considered to be more sustainable in comparison with their pure synthetic analogues [1-6]. Hybrid plastic materials are being created for many reasons. Yet, some major factors might be highlighted: rising environmental awareness, trial of incorporation of less noxious nature-derived substances into the polymer technology and economic reasons (the need to balance the costs of biodegradable polymeric matrices by manufacturers) [7-13].

As it was mentioned in the previous part [14] of this research, Hamad et al. [15] have gathered a broad range of precise information concerning blends containing poly(lactic acid) (PLA), their properties and applications. An additional subsection of the mentioned review debated on the future perspectives. The authors underlined the importance of PLA-based materials in 3D-printing and the development of porous PLA materials for biomedical applications, but they also drew attention to the importance of the recyclability and reformability of the PLA-containing blends. The last problem was also underlined in the recently published work by La Mantia et al. [16], namely, the lack of sufficient scientific background regarding the recycling of biopolymer blends. Contrary to synthetic polymer blends, PLA-containing materials exhibit a higher degradation rate, which is obviously attributed to the poly(lactic acid) content [17-19]. 
Clearly, it is more desirable to create a material which fully undergoes biodeterioration. Yet, since PLA blending is a promising modification technique enabling us to overcome some noticeable drawbacks of neat poly(lactic acid) [20-26] and hybrid bioplastic material creation helps to balance the production costs, the stabilization of PLA-based blends requires significant attention. Fortunately, similarly to pure bio- and synthetic polymers, the recycling of their blends might be carried out via mechanical or chemical recycling methods [1,16].

Nevertheless, research published by La Mantia et al. [27] confirmed that the presence of even small amounts of PLA in the poly(ethylene terephthalate) (PET) waste can noticeably affect the rheological properties of a recycled material. Moreover, scientists proved that the mechanical properties of the reproduced PET product were significantly changed.

Another example may be another work of Hamad et al. [28], which describes the properties of the PLA and polystyrene (PS) blend (PLA/PS = 50/50 wt \%). According to the presented results, multiple extrusion and injection of a PLA/PS blend resulted in a drop in the values of stress and strain at break even after two processing cycles. Yet, according to the information reported by the authors, Young's modulus was not significantly affected at this time. Unfortunately, while four processing cycles were performed, the Young's modulus showed a reduction by $26 \%$. The most noticeable property degradation was observed regarding the strain at break with $73 \%$ loss and stress at break with $79 \%$ drop. The authors attributed this phenomenon to the reduction in the polymers' molecular weight with the multiple processing cycles.

The examples given above reveal how important it is to stabilize the PLA-containing blends. Hamad et al. [15] claim that it is possible to introduce antioxidative agents through the creation of composites containing some nanoparticles, e.g., nanoclays, silver nanoparticles, metal oxides or functional biopolymers.

According to Li et al. [29,30], the stabilization of rubber-like materials may be obtained with the addition of sulfur. Nonetheless, this research is a proposal of an alternative way to achieve this goal with some eco-friendly plant-derived substances, e.g., vitamins, flavonoids and carotenes. According to the information gathered in the literature, these plant-derived substances may play the role of antioxidants and anti-aging factors [31-33]. Lately, it was found that, among others, eugenol [34], rosmarinic acid [35], phytic acid [36] or catechol [37] might be successfully applied in polymeric materials in order to prevent their properties' loss during aging. Additionally, the significant aspect of the research performed by our group is the broadening of the knowledge on the antioxidative potential of natural substances [38-43].

Recently, our team has proven that apart from the above-mentioned plant-derived compounds, hesperidin, which can be found in various citric fruits, may play the role of the effective anti-aging factor in silica-filled ethylene-norbornene copolymer (EN) based materials. Not only did it prohibit the carbonyl groups' formation during the performed 400-h-long weathering aging, but also hesperidin prevented the loss of the mechanical properties of the polymer composite during weathering (initial tensile strength of the blends at the level of $40 \mathrm{MPa}$; after $400 \mathrm{~h}$ of aging: approximately $10 \mathrm{MPa}$ for $\mathrm{EN}+$ silica and $30 \mathrm{MPa}$ while hesperidin added) [44].

Therefore, the aim of this study is to investigate the effect of different plant-derived substances, whose anti-oxidant properties have been primarily assessed by our team [45-48]. $\delta$-tocopherol (vitamin E; $\delta$-TF), curcumin $(\mathrm{CM}), \beta$-carotene $(\beta-\mathrm{CT})$ and quercetin $(\mathrm{QU})$ were chosen regarding the elastic blends of epoxidized natural rubber (ENR) and poly(lactic acid) stabilization. According to the previous research, the above-mentioned biomolecules may play the role of effective natural antioxidants, simultaneously being relatively cheap [45-48].

Thanks to the incorporation of natural additives, material biodeterioration potential described in the previous part of the research [14] might be maintained and the composites' lifespan prolonged while subjected to increased temperatures or UV irradiation. The stabilization effect was tested within the 200 h-long thermo-oxidative and UV accelerated aging processes. Thus, it was proven that some of the mentioned natural additives 
may successfully play the role of antioxidants in the investigated elastic and eco-friendly ENR/PLA blends.

\section{Materials and Methods}

\subsection{Materials}

Polymer matrixes employed in this research: epoxidized natural rubber (ENR) (Epoxyprene ENR-50; 50 mol\% epoxidation) obtained from Kumpulan Guthrie Berhad (Kuala Lumpur, Malaysia) and poly(lactic acid) (PLA), Ingeo 4043D purchased from Nature Works (Minnetonka, MN, USA). Lauric acid (97\% purity), 1,2-dimethylimidazole (highest available purity) provided by Sigma-Aldrich (Darmstadt, Germany) and elastin hydrolysate purchased from Proteina (Lodz, Poland) were used as a cross-linking system. Natural additives, namely, $\delta$-tocopherol $(\delta-\mathrm{TF}), \mathrm{CM}-\operatorname{curcumin}(\mathrm{CM}), \beta$-carotene $(\beta-\mathrm{CT})$, quercetin $(\mathrm{QU})$, of the highest available purities were purchased from Sigma-Aldrich (Darmstadt, Germany). Structures of natural additives are shown in Figure 1.

a)<smiles>Cc1cc(O)cc2c1OC(C)(CCCC(C)CCCC(C)CCCC(C)C)CC2</smiles>

c)

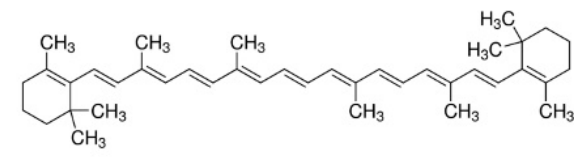

b)<smiles>COc1cc(/C=C/C(=O)CC(=O)/C=C/c2ccc(O)c(OC)c2)ccc1O</smiles>

d)<smiles>O=c1c(O)c(-c2ccc(O)c(O)c2)oc2cc(O)cc(O)c12</smiles>

Figure 1. Structures of natural additives employed in this research: (a) $\delta$-tocopherol $(\delta$-TF), (b) curcumin $(\mathrm{CM}),(\mathbf{c}) \beta$-carotene $(\beta-\mathrm{CT})$, (d) quercetin $(\mathrm{QU})$.

\subsection{Preparation of ENR/PLA Samples}

Poly(lactic acid) was conditioned for $24 \mathrm{~h}$ at $70{ }^{\circ} \mathrm{C}$ in a laboratory oven (Binder, Tuttlingen, Germany) before being incorporated into epoxidized natural rubber. All mixture components (Table 1) were mixed in a micromixer (Brabender Lab-Station from PlastiCorder with Julabo cooling system) at $160^{\circ} \mathrm{C}$ for $30 \mathrm{~min}$ (50 rpm). Next, such prepared material was put between two roll mills $\left(100 \mathrm{~mm} \times 200 \mathrm{~mm}\right.$ )—roll's temperature: $20-25^{\circ} \mathrm{C}$, friction: 1:1.1, time: $2 \mathrm{~min}$. The last step was to form the plate-like samples between two steel molds (with the use of Teflon sheets separating the mixture from the mold) in a hydraulic press—temperature: $160{ }^{\circ} \mathrm{C}$, time: $60 \mathrm{~min}$, pressure: $125 \mathrm{bar}$.

Table 1. Composition of the polymer blend mixtures prepared for analysis in this research. Abbreviations: ENR — epoxidized natural rubber, PLA—-poly(lactic acid), LA-lauric acid, DMI1,2-dimethylimidazole, $\mathrm{EH}$ - elastin hydrolysate, $\delta$-TF- $\delta$-tocopherol, $\mathrm{CM}$-curcumin, $\beta$-CT- $\beta$ carotene, QU—quercetin, phr—per hundred rubber (it means: for one hundred parts by weight of rubber there are $\mathrm{x}$ parts by weight of the substance).

\begin{tabular}{|c|c|c|c|c|c|c|c|c|c|}
\hline \multirow{2}{*}{ Sample } & \multicolumn{9}{|c|}{ Polymer Mixture Composition [phr] } \\
\hline & ENR & PLA & LA & DMI & EH & $\delta$-TF & $\mathbf{C M}$ & $\beta-\mathrm{CT}$ & QU \\
\hline ENR/PLA & 100 & 75 & 3 & 0.6 & 0.6 & $-\ldots$ & --- & --- & $-\ldots$ \\
\hline$+\delta$-tocopherol & 100 & 75 & 3 & 0.6 & 0.6 & 3 & --- & --- & $-\ldots$ \\
\hline+ curcumin & 100 & 75 & 3 & 0.6 & 0.6 & $-\ldots$ & 3 & $-\ldots$ & $-\ldots$ \\
\hline$+\beta$-carotene & 100 & 75 & 3 & 0.6 & 0.6 & $-\ldots$ & --- & 3 & $-\ldots$ \\
\hline + quercetin & 100 & 75 & 3 & 0.6 & 0.6 & - - - & $-\ldots$ & $-\ldots$ & 3 \\
\hline
\end{tabular}




\subsection{Accelerated Aging of the Materials}

\subsubsection{Thermo-Oxidative Aging}

Thermo-oxidative aging was performed in a laboratory oven (Binder, Tuttlingen, Germany) at $70{ }^{\circ} \mathrm{C}$ for $200 \mathrm{~h}$. Four samples of each ENR/PLA blend were placed in an oven and were taken out individually after, respectively, $50 \mathrm{~h}, 100 \mathrm{~h}, 150 \mathrm{~h}$ and $200 \mathrm{~h}$.

\subsubsection{UV Irradiation}

ENR/PLA blend samples were mounted in the special holders in the Atlas UV 2000 apparatus (Duisburg, Germany). Again, specimens were taken out individually after, respectively, $50 \mathrm{~h}, 100 \mathrm{~h}, 150 \mathrm{~h}$ and $200 \mathrm{~h}$. The aging cycle consisted of two alternating segments: day segment $\left(240 \mathrm{~min}, 60^{\circ} \mathrm{C}\right.$, UV irradiation: $\left.0.7 \mathrm{~W} / \mathrm{m}^{2}\right)$ and night segment (120 $\mathrm{min}, 50^{\circ} \mathrm{C}$, no UV radiation).

\subsection{Methods of Polymer Blend Sample Characterization}

\subsubsection{Swelling in Toluene}

The experiment aim was to measure the weight of the sample immersed in toluene before and after the swelling process. Thus, 4 samples of different shapes of each material were prepared (30-40 mg). The samples were weighed before the measurement $\left(\mathrm{m}_{1}\right)$ and then put into the vessel with toluene. When $48 \mathrm{~h}$ were over, they were taken out and weighed in the swollen state $\left(\mathrm{m}_{2}\right)$. The excess toluene was cleaned with the filter paper and each sample was immersed in ethyl ether for 1-2 s. Subsequently, the samples were dried to constant weight in an oven at $50{ }^{\circ} \mathrm{C}$ for $96 \mathrm{~h}$ and weighed when the time was over $\left(\mathrm{m}_{3}\right)$. In order to analyze the potential cross-linking density, two parameters were calculated: $\mathrm{m}_{\text {rise }}=\mathrm{m}_{2}-\mathrm{m}_{1}\left(\mathrm{~m}_{\text {rise }}\right.$ reveals how much the sample is swollen in the solvent), $\mathrm{m}_{\text {loss }}=\mathrm{m}_{3}-\mathrm{m}_{1}$ ( $\mathrm{m}_{\text {loss }}$ informs about the low molecular weight compounds washed out during the swelling in toluene).

\subsubsection{Contact Angle Measurement}

Contact angle measurements were carried out for: distilled water and 1,4-diiodomethane (droplet volume set for: $1 \mu \mathrm{L}$ ). Before the measurement, surfaces of polymer composite samples were cleaned with the use of acetone. OCA 15EC goniometer by DataPhysics Instruments $\mathrm{GmbH}$ (Filderstadt, Germany) equipped with single direct dosing system $(0.01-1 \mathrm{~mL}$ B. Braun syringe, Hassen, Germany) was employed. Surface free energy is calculated with the OwensWendt-Rabel-Kaelble (OWRK) method.

\subsubsection{Tensile Tests}

Mechanical properties, namely, tensile strength (TS) and elongation at break (Eb), were determined based on the ISO-37 with the use of a Zwick-Roell 1435 device (Ulm, Germany). Tests were carried out on a "dumbbell" shape (thickness: $1 \mathrm{~mm}$, width of measured fragment: $4 \mathrm{~mm}$, length of measured fragment: $25 \mathrm{~mm}$, total length: $75 \mathrm{~mm}$, width at the ends: $12.5 \mathrm{~mm}$ ). The samples were stretched at a speed of $500 \mathrm{~mm} / \mathrm{min}$. On the basis of obtained results, the aging coefficient $K$ was calculated according to the Equation (1) as a quotient of the product of TS and $E b$ after and before the performed aging process [49]:

$$
K=\frac{(T S \cdot E b)_{\text {after ageing }}}{(T S \cdot E b)_{\text {before ageing }}}
$$

\subsubsection{Color Change}

Spectrophotometer UV-VIS CM-36001 from Konica Minolta. Sample color was described with the CIE-Lab system ( $L$-lightness, $a$-red-green, $b$ - yellow-blue) employed 
in this research. Then, color difference $(\Delta E)$, whiteness index $\left(W_{i}\right)$, chroma $\left(C_{a b}\right)$ and hue angle $\left(h_{a b}\right)$ values were calculated according to the equations given below (2-4):

$$
\begin{gathered}
\Delta E=\sqrt{(\Delta a)^{2}+(\Delta b)^{2}+(\Delta L)^{2}} \\
W_{i}=100-\sqrt{a^{2}+b^{2}+(100-L)^{2}} \\
C_{a b}=\sqrt{a^{2}+b^{2}} \\
h_{a b}=\left\{\begin{array}{c}
\operatorname{arctg}\left(\frac{b}{a}\right), \text { when } a>0 \wedge b>0 \\
180^{\circ}+\operatorname{arctg}\left(\frac{b}{a}\right), \text { when }(a<0 \wedge b>0) \vee(a<0 \wedge b<0) \\
360^{\circ}+\operatorname{arctg}\left(\frac{b}{a}\right), \text { when } a>0 \wedge b<0
\end{array}\right.
\end{gathered}
$$

\subsubsection{Mass Loss during the Degradation Process}

In order to observe some mass changes, while samples were subjected to elevated temperature and UV irradiation, specially prepared samples were being weighed at the following times during the accelerated aging processes: $0 \mathrm{~h}, 50 \mathrm{~h}, 100 \mathrm{~h}, 150 \mathrm{~h}$ and $200 \mathrm{~h}$.

\subsubsection{Scanning Electron Microscopy (SEM) Analysis}

Scanning electron microscopy (Zeiss, ULTRA Plus, Oberchoken, Germany) was employed in order to examine the morphology of prepared ENR/PLA blend samples. Magnification was 250 and 1000 times.

\section{Results and Discussion}

The previous part [14] of this research study showed that it is possible to control the degradation rate of ENR/PLA blends with plant-derived fibers while subjected to increased temperature or UV irradiation, simultaneously causing their easier biodeterioration. Moreover, it was revealed that thanks to the organic-inorganic phase ratio, the control over the material degradation rate during thermo-oxidation and UV aging could be enabled. However, the incorporation of natural fibers into ENR/PLA blends without any additional anti-aging substances was the reason for their lower resistance to the two above-mentioned factors (temperature, UV), and only MMT was found to be able to prolong the lifespan of analyzed ENR/PLA blends.

Therefore, in this part of the research, different substances leading to the ENR/PLA blends' stabilization are investigated. Some natural compounds of the potentially antioxidative properties [31-33] have been chosen: $\delta$-tocopherol $(\delta-\mathrm{TF})$, curcumin $(\mathrm{CM}), \beta$-carotene $(\beta-C T)$, quercetin $(\mathrm{QU})$. Their effect on the ENR/PLA blend properties before and after the accelerated aging processes is shown below.

Similarly to the previous part [14] of the study, analyzed polymer blends were investigated regarding the properties which may indicate some information about the degradation of the ENR/PLA blends during the accelerated aging processes. A swelling experiment was caried out in order to assess the cross-linking density as the crosslinks may stabilize the structure of the polymer network and prevent quick material degradation [50]. Moreover, the polymer composites exhibiting a higher polar component of surface free energy are known to be more prone to degradation during the aging processes regarding the ongoing radical reactions [51], e.g., oxidation. Thus, surface free energy was examined with the employment of contact angle technique. Finally, it was examined if the natural additives proposed in this research influence the mechanical performance of the analyzed ENR/PLA blends. Then, the effect of thermo-oxidative and UV accelerated aging was tested.

\subsection{Characterization of Specimens before the Accelerated Aging Process}

The swelling experiment, tensile tests and contact angle measurements were carried out in order to, respectively, assess the cross-linking density of the prepared material, 
investigate the influence of natural additives on the blends' mechanical performance and predict the degradation potential of the prepared specimens.

In Figure 2a, two parameters are presented: mass rise after the swelling process, which is proportional to the number of bonds created between different macromolecules, and mass loss during the swelling process, which is proportional to the amount of low molecular weight particles washed out in the swollen state [52]. Thus, it may be concluded that $\delta$-TF and QU did not affect cross-linking density in a significant way as the samples are swollen similarly to the reference ENR/PLA blend. At the same time, in the case of the ENR/PLA samples with the addition of $C M$ and $\beta-C T$, a great drop in mass rise after the swelling process was detected. This may indicate that these two compounds (CM, $\beta-C T)$ led to the significant improvement in cross-linking density.

a)

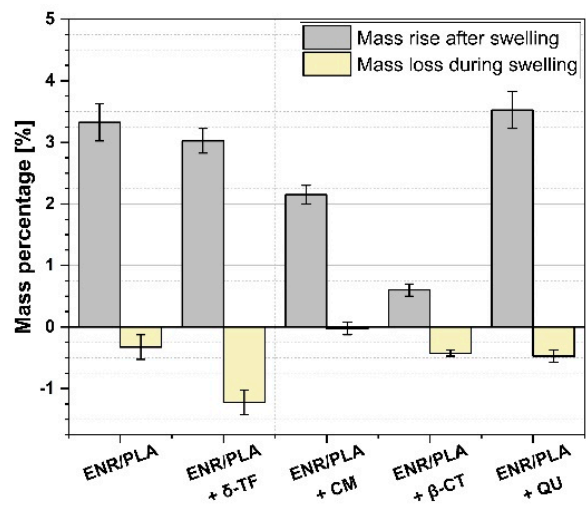

c)

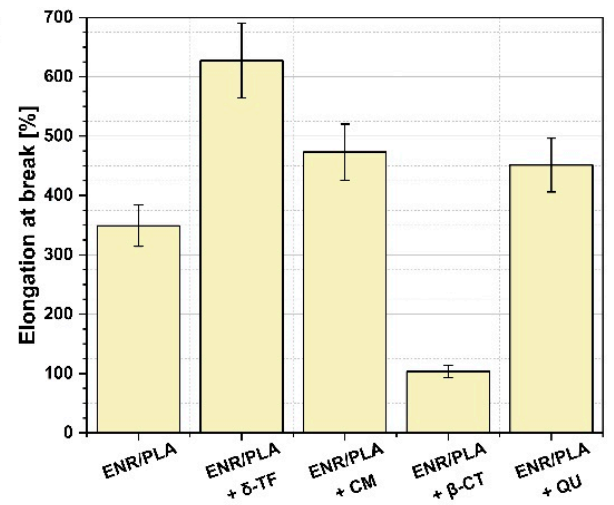

b)

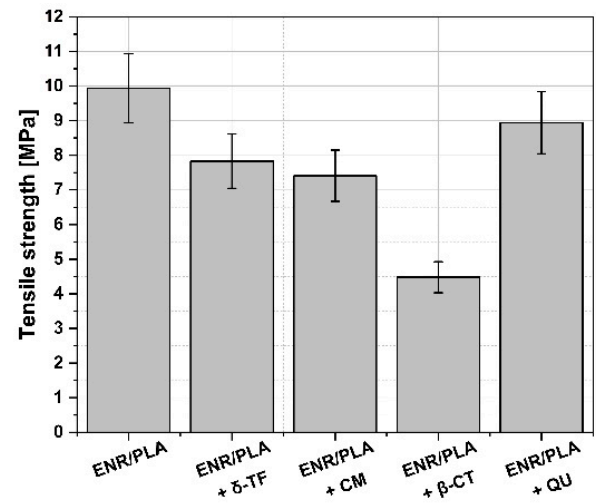

d)

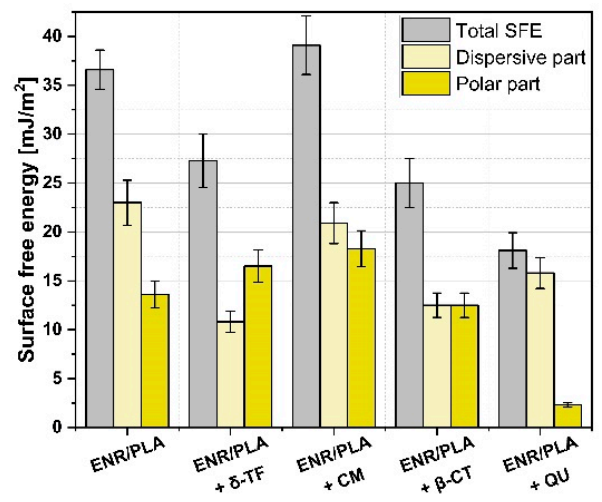

Figure 2. ENR/PLA blend properties before the accelerated aging processes: (a) analysis of the swelling experiment, (b) tensile strength of analyzed specimens, (c) elongation at break of investigated samples, (d) surface free energy and its components analysis.

Furthermore, analyzing the data concerning the mass loss during the swelling process, it is visible that different amounts of low-molecular weight substances were washed out during the swelling of ENR/PLA. The reason for the observed differences could be the varied rate in the migration of the applied compounds to the surface of the polymer blend [52], e.g., the mass loss of the CM-loaded sample is the lowest, while for $\delta$-TF addition the highest rinsing effect is detected.

Moving forward and analyzing the mechanical properties of prepared ENR/PLA blends (Figure $2 b, c)$, some more variations between the samples are revealed. The specimen which was expected to have cross-linked the most and exhibited the lowest swelling degree, namely, ENR/PLA $+\beta-C T$, was revealed to have the lowest tensile strength and elongation at break. This could be explained with the fact that $\beta$-CT possesses in its structure many $\mathrm{C}=\mathrm{C}$ bonds that can easily take part in cross-linking during the vulcanization process, therefore stiffening the material and preventing its elongation [53]. At the same time, the rest of the prepared samples revealed similar values of tensile strength on the level of the ENR/PLA reference blend or slightly lower. 
More variations can be found regarding the elongation at break (Figure 2c). Each natural additive, apart from $\beta-\mathrm{CT}$, enabled obtaining the material which can elongate more than the reference ENR/PLA blend. The highest elongation is achieved in the case of the sample filled with $\delta$-TF. This could be explained with the fact that its molecule possesses in its structure a long carbon chain that may work as a plasticizing agent [18].

The plasticization effect of the analyzed ENR/PLA blend specimens with an addition of $\delta$-TF and CM may also be visible regarding the tensile stress values for the elongations of $100 \%, 200 \%$ and $300 \%$ (Table 2). In the case of the samples mentioned above, the tensile stress at any point is lower than for the reference ENR/PLA polymer blend.

Table 2. Tensile stress at elongation of $100 \%, 200 \%, 300 \%$ for the unfilled and filled ENR/PLA blend samples.

\begin{tabular}{cccc}
\hline \multirow{2}{*}{ Sample } & \multicolumn{3}{c}{ Tensile Stress [MPa] at Elongation of: } \\
\cline { 2 - 4 } & $\mathbf{1 0 0 \%}$ & $\mathbf{2 0 0 \%}$ & $\mathbf{3 0 0} \%$ \\
\hline ENR/PLA & $4.5 \pm 0.2$ & $6.7 \pm 0.3$ & $8.8 \pm 0.2$ \\
ENR/PLA + $\delta$-tocopherol & $3.3 \pm 0.1$ & $4.7 \pm 0.2$ & $5.8 \pm 0.2$ \\
ENR/PLA + curcumin & $3.8 \pm 0.4$ & $5.2 \pm 0.5$ & $6.3 \pm 0.3$ \\
ENR/PLA + $\beta$-carotene & $4.0 \pm 0.3$ & - & - \\
ENR/PLA + quercetin & $5.2 \pm 0.3$ & $6.8 \pm 0.4$ & $8.0 \pm 0.5$ \\
\hline
\end{tabular}

Moreover, according to the data gathered in Figure 2d, some variations regarding the surface free energy and both its components are revealed. Taking into consideration the presented results, specimens loaded with $\delta$-TF and $\beta$-CT seem to be more hydrophilic. This is evidenced with contact angle measurements (Table 3 ) as these materials exhibit easier wetting with water (lower value of contact angle). On the other hand, QU incorporation into the ENR/PLA blend leads to the surface hydrophobization and the contact angle with water rises up to $(101 \pm 4)^{\circ}$, which is the highest of observed values.

Table 3. Water and diiodomethane contact angles for the unfilled and filled ENR/PLA blend samples.

\begin{tabular}{ccc}
\hline \multirow{2}{*}{ Sample } & \multicolumn{2}{c}{ Contact Angle [ ${ }^{\circ}$ ] } \\
\cline { 2 - 3 } & Water & Diiodomethane \\
\hline ENR/PLA & $70 \pm 3$ & $57 \pm 2$ \\
ENR/PLA + $\delta$-tocopherol & $67 \pm 3$ & $82 \pm 1$ \\
ENR/PLA + curcumin & $65 \pm 2$ & $60 \pm 2$ \\
ENR/PLA + $\beta$-carotene & $82 \pm 1$ & $80 \pm 2$ \\
ENR/PLA + quercetin & $101 \pm 4$ & $80 \pm 3$ \\
\hline
\end{tabular}

Samples with the addition of $\delta$-TF, $\beta$-CT and QU exhibit lower total surface free energy in comparison with the reference ENR/PLA blend. The only material containing natural additives and exhibiting surface properties similar to the reference sample is ENR/PLA + CM. The lowest value for the polar component of surface free energy is detected for the sample loaded with QU, which may indicate the highest stabilization potential regarding further aging tests (potentially less polar active centers prone to oxidation) [50].

Finally, the morphology of the prepared ENR/PLA blend samples was examined with the use of the SEM method. Images captured during the measurement are presented in Figure 3. The magnifications of 250 and 1000 times were applied.

Importantly, no signs of the blend components' separation can be denoted. This means that the mixing process of ENR and PLA was sufficient and effective. 
a)

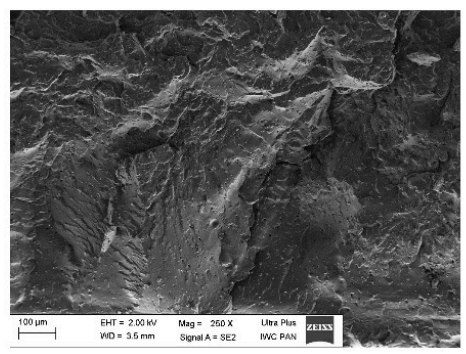

c)

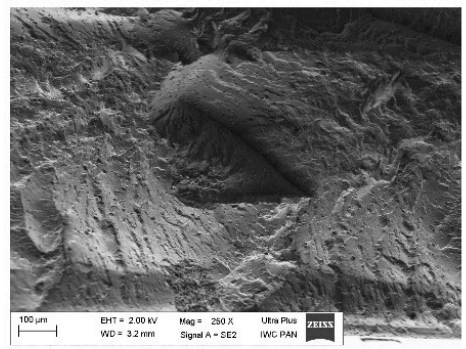

e)

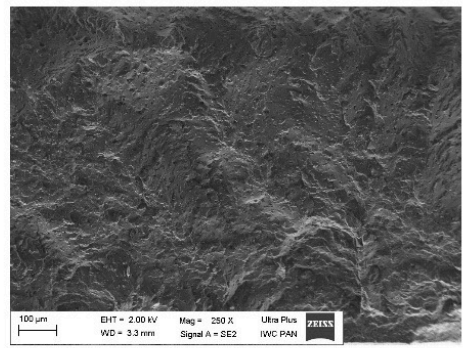

g)

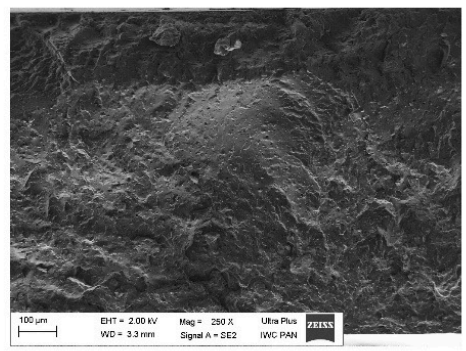

i)

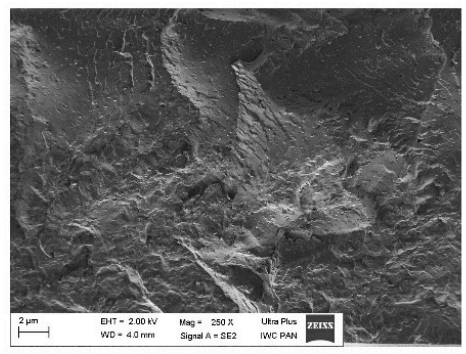

b)

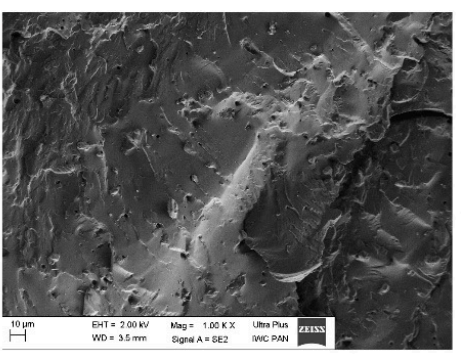

d)

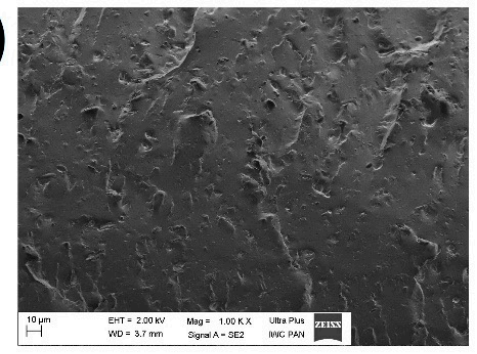

f)

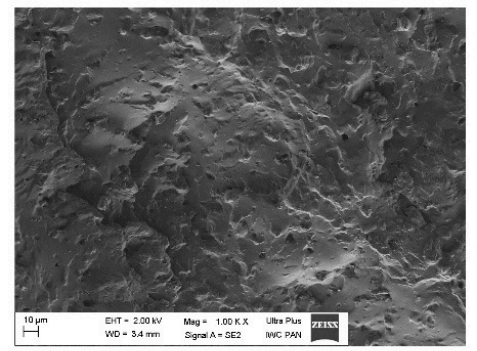

h)

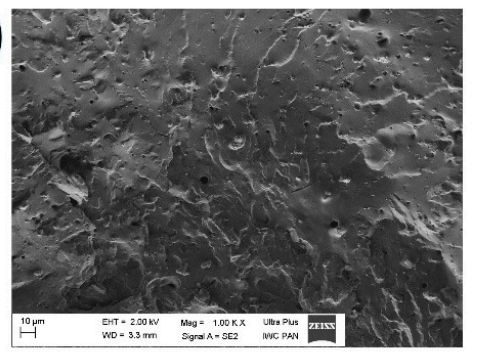

j)

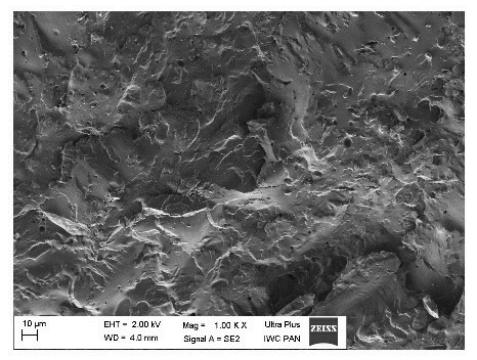

Figure 3. SEM images for: reference sample of ENR/PLA blend (a,b), ENR/PLA + $\delta$-tocopherol $(\mathbf{c}, \mathbf{d})$, ENR/PLA + curcumin $(\mathbf{e}, \mathbf{f})$, ENR/PLA + $\beta$-carotene $(\mathbf{g}, \mathbf{h})$, ENR/PLA + quercetin $(\mathbf{i}, \mathbf{j})$ with magnifications, respectively, 250 and 1000.

Moreover, performed morphology analysis proved that the natural additives employed in this study are fairly well dispersed in the polymer matrix and no big aggregates are present. Nonetheless, some inclusions might be denoted, e.g., specimens filled with $\beta-C T$ and QU.

It is also visible that the blends' surfaces are characterized by different regularity. The reference sample of ENR/PLA blend has an uneven and ragged surface, while specimens prepared with the addition of natural substances seem to be smoother. The only exception is the sample of QU-modified ENR/PLA blend. 


\subsection{Characterization of the Aging Impact}

ENR/PLA blend samples were subjected to accelerated aging of two types: thermooxidative (increased temperature in the presence of air) and UV (chamber with UV lamps; $340 \mathrm{~nm}$ ). During the aging processes, radical reactions might be initiated via temperature or UV irradiation and contribute to polymer chains' crosslinking, oxidation or scission. This leads to some irreversible changes in the properties of the material subjected to the aging process [54].

The performed accelerated aging lasted for $200 \mathrm{~h}$, and during the processes, after each $50 \mathrm{~h}$, the tensile properties, mass of the polymer blend and color parameters were tested in order to assess the rate of the degradation process (Figure 4) and if the accelerated aging caused crosslinking resulting in the material stiffening or oxidation/scission that may be evidenced with, e.g., lowering mechanical performance of the investigated polymer blend $[55,56]$.

a)

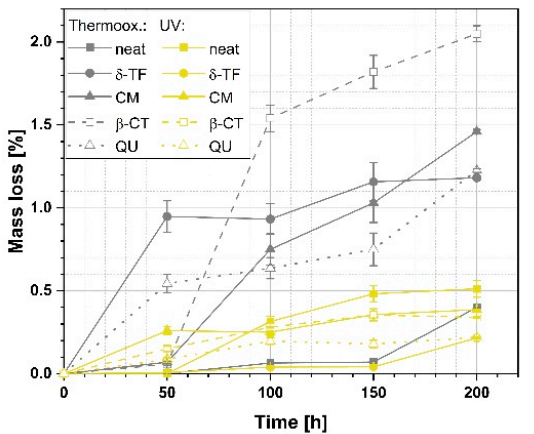

c)

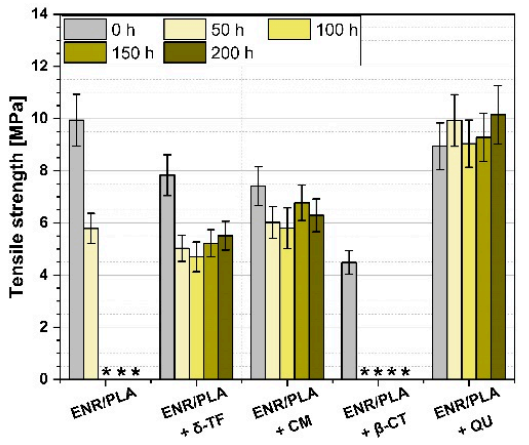

e)

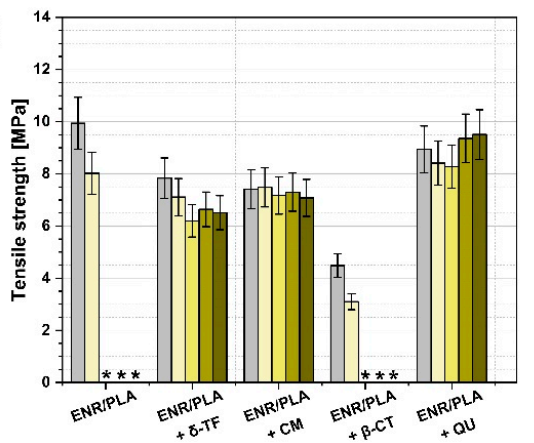

b)

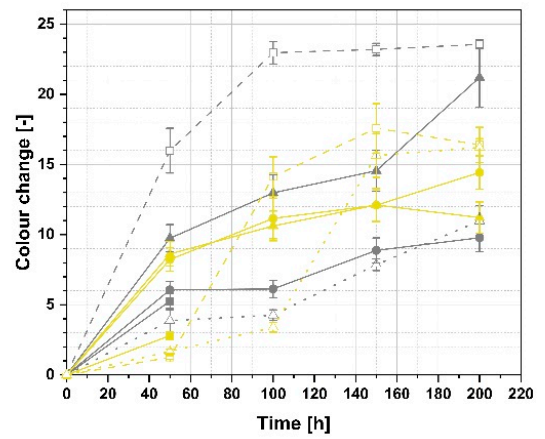

d)

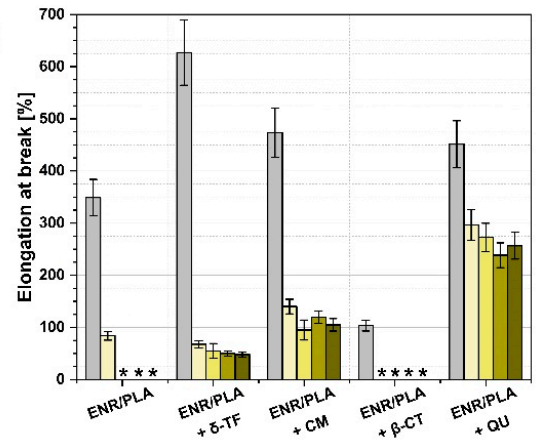

f)

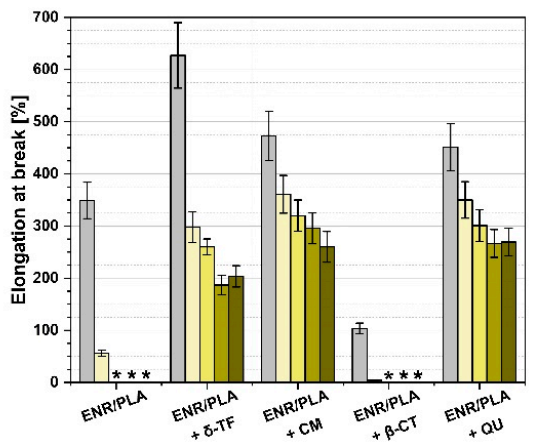

Figure 4. Investigation of the ENR/PLA blends' properties before and after the accelerated aging processes: (a) mass loss during the thermo-oxidative and UV aging, (b) color change during the thermo-oxidative and UV aging, (c) tensile strength changes and (d) elongation at break variations during the thermo-oxidative aging, (e) tensile strength changes and (f) elongation at break variations during the UV aging. *-sample too brittle to be examined with the selected method; the measurement was impossible.

Regarding the data gathered in Figure 4a, some differences between thermo-oxidative and UV aging could be found. Firstly, higher mass loss might be detected in the case of 
the first type of aging. It might be explained with the moisture content in the hydrophilic components of the loaded ENR/PLA blend $[57,58]$, which is lost while the sample is subjected to the elevated temperature.

For thermo-oxidative aging, the highest mass variations could be evidenced in the case of $\beta$-CT and $\delta$-TF-loaded ENR/PLA blends. In turn, CM incorporation seems to cause a slower mass decrease. Yet, after $200 \mathrm{~h}$ of aging, the mass loss of the CM-filled specimen achieved a value higher than that observed for $\delta$-TF addition.

On the contrary, regarding the UV aging, weight loss occurs considerably slower and steadier. Moreover, the mass decrease values are the highest in the case of the reference ENR/PLA polymer blend, which means that the natural substances added to the composition could have possibly acted as successful stabilizers during the UV aging.

Moving forward to the graphs presented in Figures $4 \mathrm{~b}$ and 5 , the detected color changes are quite significant for some polymer blend samples, and in some cases they reach the value of color change of approximately 20, e.g., $\delta$-TF and CM-loaded specimens. Moreover, they become darker or lighter depending on the aging.

a)

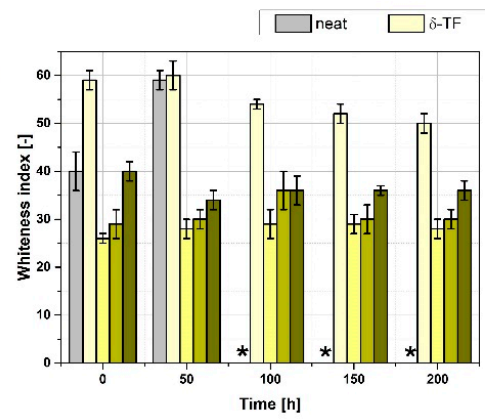

c)

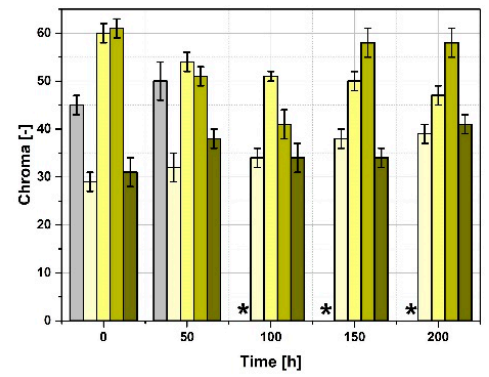

e)

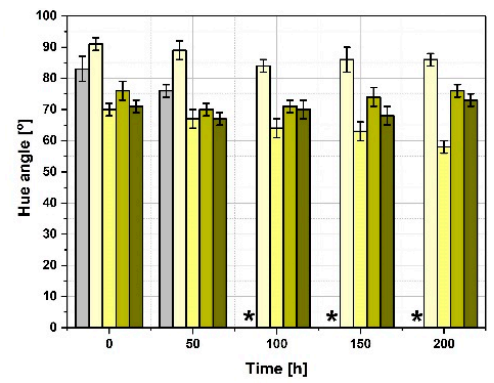

b)

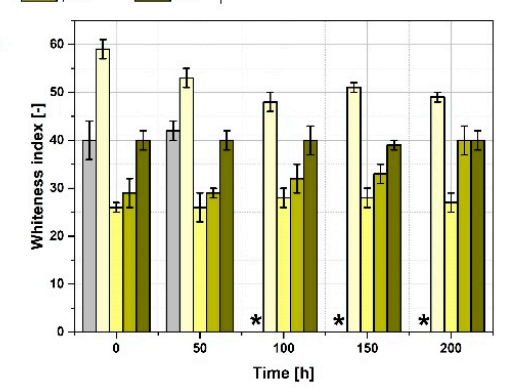

d)

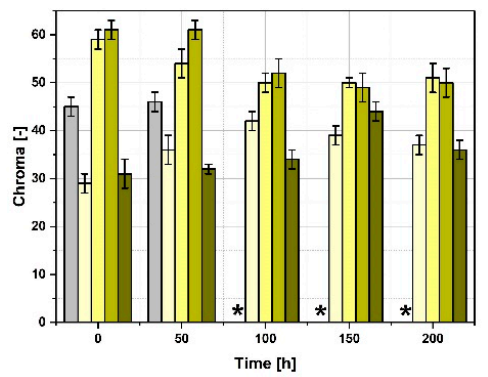

f)

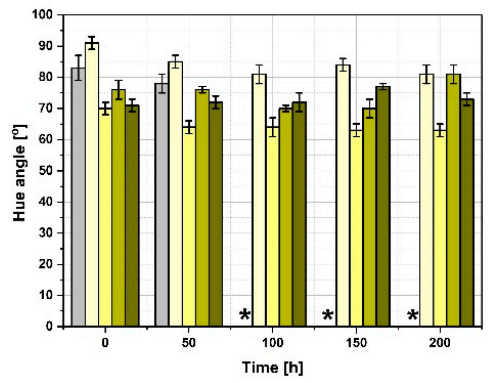

Figure 5. Additional parameters, namely, whiteness index, chroma, hue angle, contributing to color change of ENR/PLA blends and their variations during the thermo-oxidative (respectively: $(\mathbf{a}, \mathbf{c}, \mathbf{e})$ ) and UV (respectively: $(\mathbf{b}, \mathbf{d}, \mathbf{f}))$ accelerated aging processes. * - sample too brittle to be examined with the selected method; the measurement was impossible.

A color change higher than 3 means that variations evidenced for these samples could be easily visible with the human eye. Furthermore, it was observed that all substances steadily and constantly change their color upon the carried out aging processes (Figures $4 \mathrm{~b}$ and 6 ). Thus, the applied natural substances, apart from their application as natural antioxidants, might be very promising regarding the bio-based aging indicators for, e.g., food packaging $[48,59]$. 


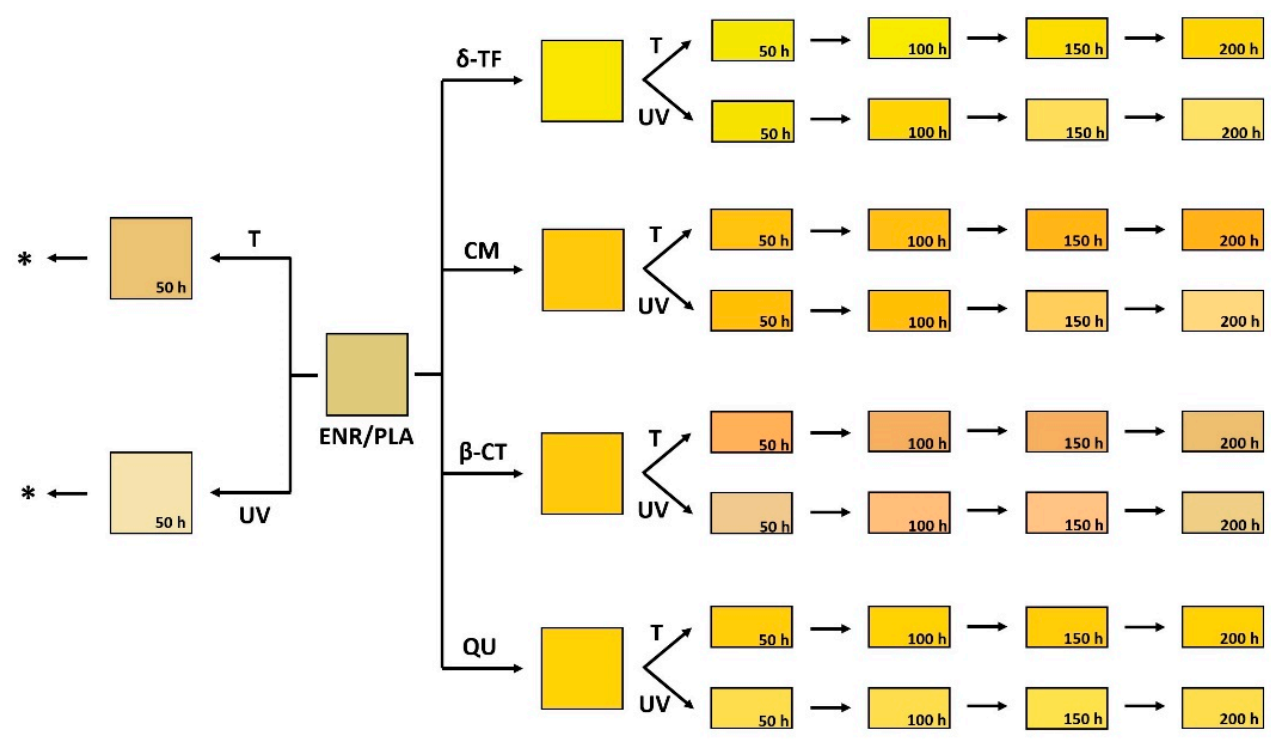

Figure 6. Color change representation for the prepared ENR/PLA blends before and after the accelerated thermo-oxidative (T), as well as UV-initiated (UV) aging processes. ${ }^{*}$-sample destroyed significantly.

It is worth noticing that samples of the reference ENR/PLA polymer blend after $100 \mathrm{~h}$, $150 \mathrm{~h}$, and $200 \mathrm{~h}$ of thermo-oxidative and UV aging were degraded noticeably. Thus, it was impossible to investigate the properties of the reference ENR/PLA polymer blend as it became too brittle to carry out the measurement.

Additionally, more data regarding the color change described with the parameters such as whiteness index, chroma and hue angle are presented in Figure 5. Based on the gathered information, some interesting conclusions might be made, e.g., the ENR/PLA + $\delta$-TF specimen subjected to thermo-oxidation becomes darker and the color is more intense with the aging time. On the other hand, the color of the same sample subjected to UV irradiation becomes lighter. The color change representation is shown in Figure 6.

Moving forward and analyzing the mechanical properties of the prepared ENR/PLA blends during the aging process, it is visible that the reference material and the sample with the addition of $\beta$-CT are the most affected by the performed accelerated aging. Fortunately, $\delta$-TF, CM and QU exhibit a stabilizing effect to a certain extent, depending on the used natural additive (Figure $4 \mathrm{c}-\mathrm{f}$ ).

According to the gathered results, the most effective stabilization is visible for the QUfilled ENR/PLA blend. The sample's performance slightly rose during the aging process and the elongation at break decreased the least in comparison with different samples.

The improvement in tensile strength upon the aging process observed for the QUloaded sample might be explained with the previously evidenced ability of quercetin to cross-link ENR-containing blends [60]. On the other hand, the negative effect of $\beta$-CT on the ENR/PLA blend's properties during the aging process might be explained with two factors: the above-mentioned ability to take part in the crosslinking process (and, thus, over-crosslinking of the polymer blend) and possible prooxidative behavior related to the not properly adjusted amount of $\beta-\mathrm{CT}$ in the polymeric mixture [61-63].

Considering Figure $4 c, d$, which refer to the aging performed in the elevated temperature, samples filled with $\delta$-TF and $\mathrm{CM}$ become stiffer during the aging process as the tensile strength stays almost at the same level and elongation at break drops significantly.

This phenomenon may be explained with the ability of quercetin reported in the literature to crosslink the ENR [60]. It is possible that increased temperature or UV irradiation during the performed accelerated aging processes could have initiated the crosslinking of the polymer matrix and, thus, further stabilized the ENR/PLA blend. 
In turn, Figure 4e,f refer to the UV aging. It is visible that QU, again, exhibits a stabilizing effect and prevents the mechanical properties' loss. However, CM also effectively delays the material degradation, leading to keeping the tensile strength at the same level during the aging process.

A perfect confirmation for the stabilizing effect of these two compounds is presented in Figure 7 . The values of the $K$ coefficient, which compares the mechanical properties before and after the aging process, are presented for the samples prepared with and without potential natural anti-aging substances. Therefore, according to the data gathered in Figure 7 , the positive effect of some among the applied compounds might be found (certain natural anti-aging substances are able to prevent a material's significant performance drop during the aging processes). Additionally, information gathered in Table 4 helps to compare the results presented in this research with the previously carried out study, which debates on plant fibers' incorporation into ENR/PLA blends.
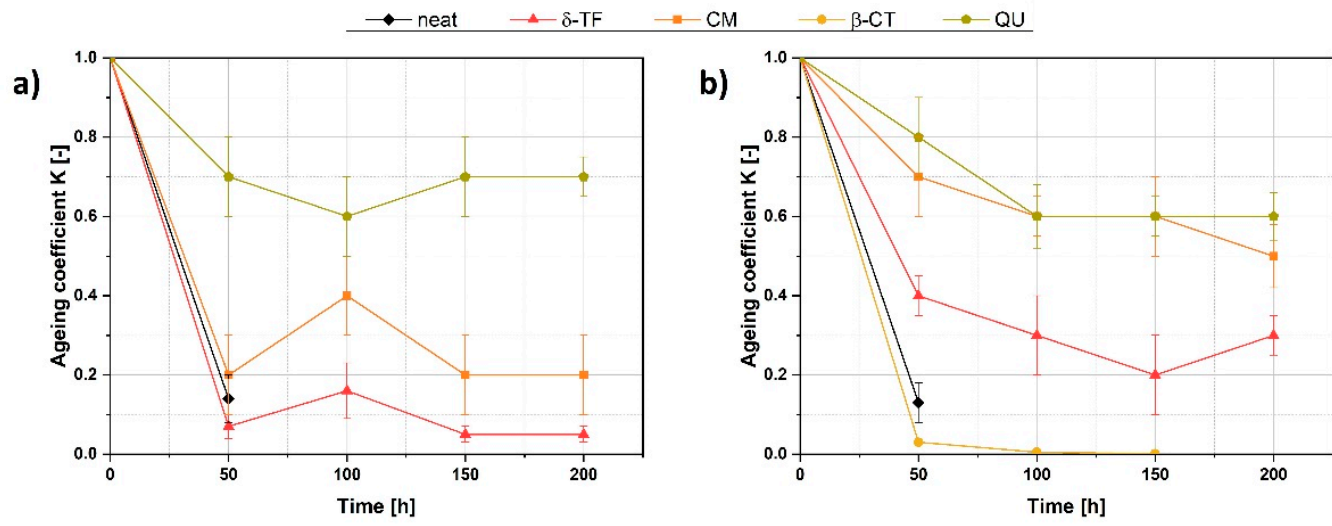

Figure 7. Aging coefficients attributed to the filled and unfilled ENR/PLA specimens at a certain aging time during thermo-oxidative (a) and UV (b) aging.

Table 4. Comparison of aging coefficient values with the results presented in the previous part of the study [14]; CF—cellulose fibers, FF—flax fibers, MMT—montmorillonite. * - sample too brittle to be examined with the selected method; the measurement was impossible.

\begin{tabular}{|c|c|c|c|c|}
\hline \multirow{2}{*}{ Sample ENR/PLA } & \multicolumn{4}{|c|}{ Aging Coefficient $K[-]-$ Thermo-Oxidation } \\
\hline & $50 \mathrm{~h}$ & $100 \mathrm{~h}$ & $150 \mathrm{~h}$ & $200 \mathrm{~h}$ \\
\hline$+\mathrm{CF}[14]$ & * & * & * & * \\
\hline$+\mathrm{FF}[14]$ & $0.004 \pm 0.002$ & $0.002 \pm 0.001$ & $0.002 \pm 0.001$ & * \\
\hline + FF + MMT [14] & $0.3 \pm 0.1$ & $0.3 \pm 0.1$ & $0.20 \pm 0,08$ & $0.20 \pm 0,07$ \\
\hline \multirow{2}{*}{ Sample ENR/PLA } & \multicolumn{4}{|c|}{ Aging Coefficient $K$ [-]-UV Irradiation } \\
\hline & $50 \mathrm{~h}$ & $100 \mathrm{~h}$ & $150 \mathrm{~h}$ & $200 \mathrm{~h}$ \\
\hline$+\mathrm{CF}[14]$ & $0.03 \pm 0.01$ & $0.06 \pm 0.03$ & $0.02 \pm 0.01$ & * \\
\hline + FF [14] & $0.02 \pm 0.01$ & $0.06 \pm 0.02$ & $0.06 \pm 0.02$ & $0.01 \pm 0.01$ \\
\hline + FF + MMT [14] & $0.2 \pm 0.1$ & $0.18 \pm 0.07$ & $0.15 \pm 0.05$ & $0.21 \pm 0.08$ \\
\hline
\end{tabular}

It is clearly visible that QU is the substance of the highest stabilizing potential and it can be applied while the material is subjected to elevated temperature or UV irradiation. The maximum shift of the aging coefficient detected for the QU-loaded sample is from 1 to $0.6 \pm 0.3$ for $200 \mathrm{~h}$-lasting UV aging and to $0.7 \pm 0.3$ for thermo-oxidative aging, which means a mechanical performance loss by, respectively, $40 \%$ and $30 \%$. QU stabilizing activity may be explained as a synergic effect of antioxidative properties and the ability to crosslink ENR [47]. Moreover, according to the gathered data, CM might also be a quite efficient anti-aging factor for ENR/PLA blends while considering UV-resistance (the performance drop by approximately 50\%). 


\subsection{Possible Stabilization Effect of the Natural Substances Employed in This Research}

The aim of this subsection is to clarify the possible stabilization behavior of the natural substances employed in this research and provide the reader with some useful information regarding the polymer blends' aging process analysis and the probable stabilization behavior of plant-derived substances employed in this research (Figure 8).

a)
)

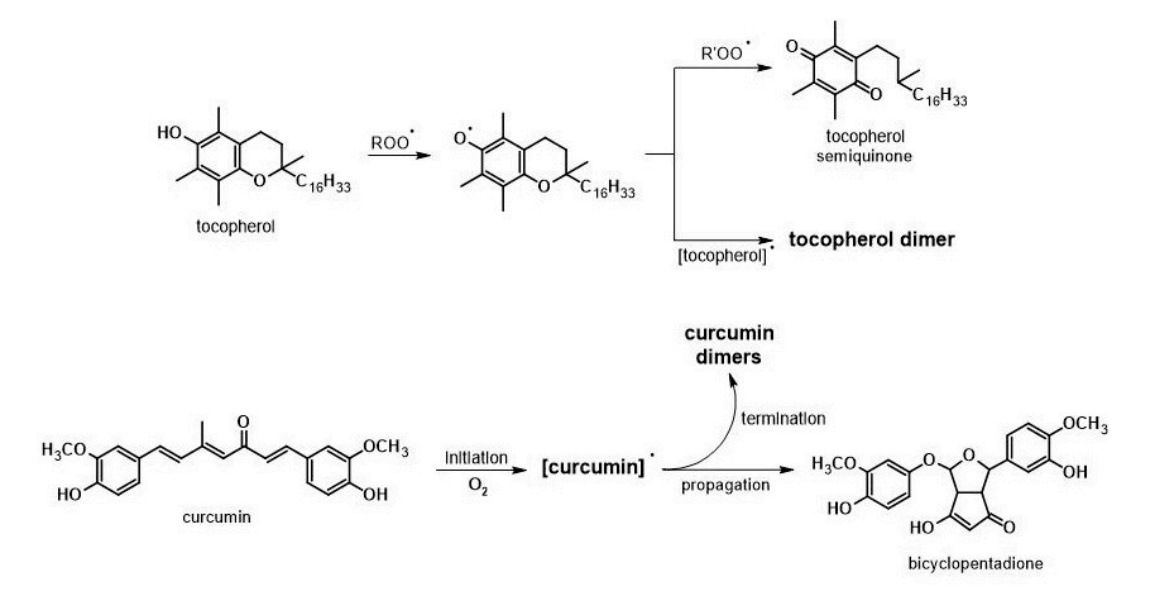

c)

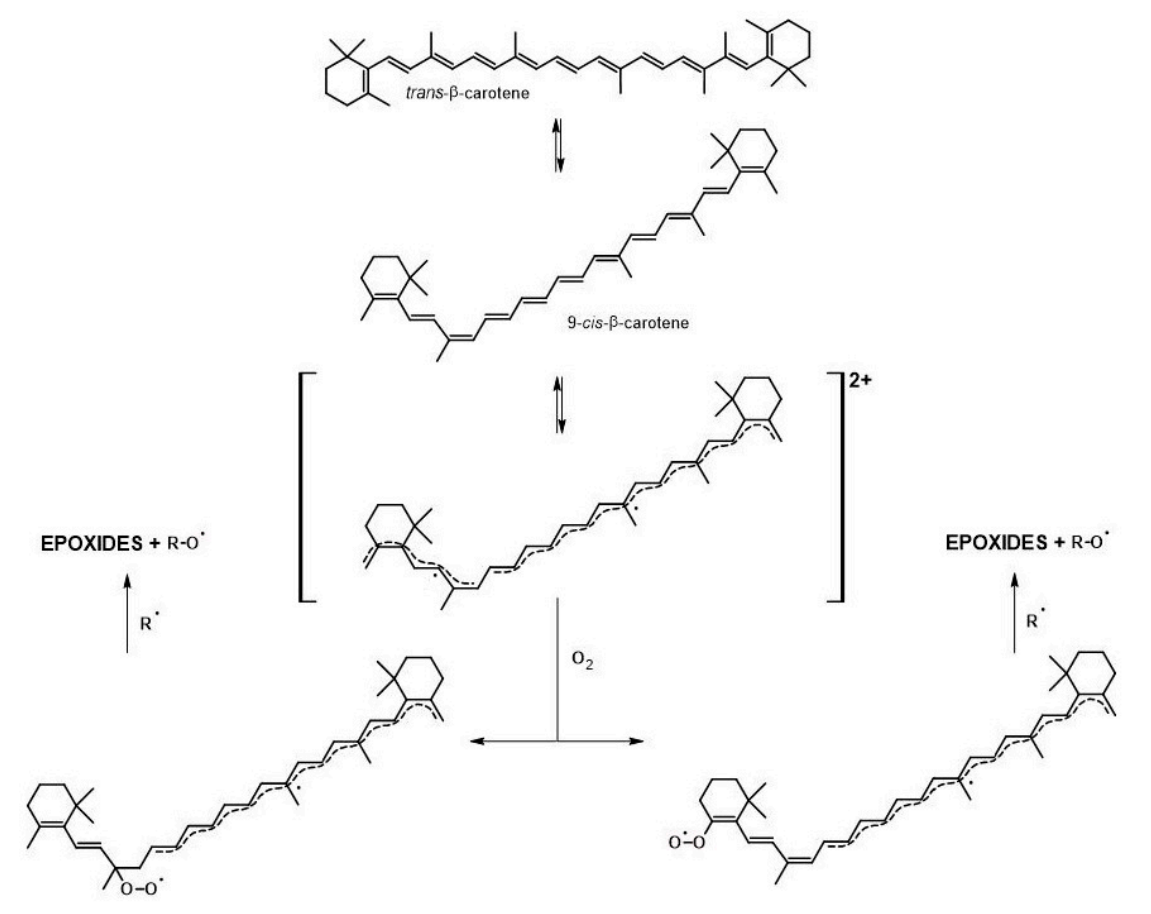

d)

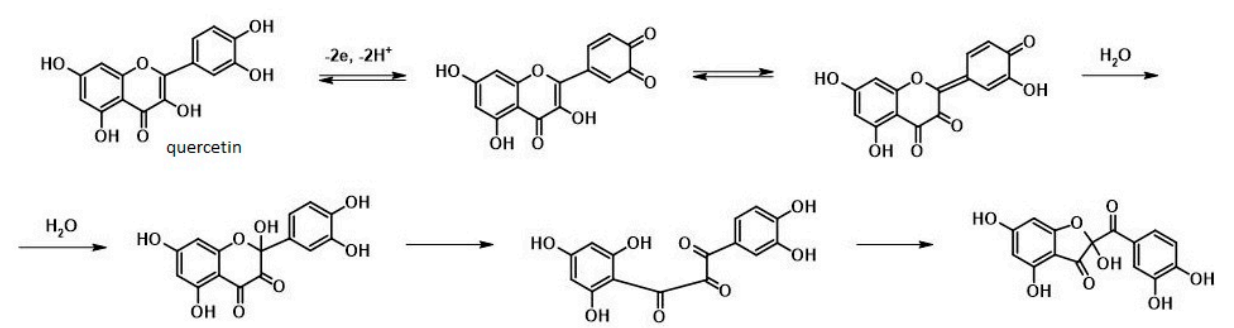

Figure 8. Possible mechanisms of free radical scavenging and oxidation behavior according to the available literature data: (a) $\delta$-tocopherol $(\delta-\mathrm{TF}),(\mathbf{b})$ curcumin $(\mathrm{CM}),(\mathbf{c}) \beta$-carotene $(\beta-\mathrm{CT})$, (d) quercetin (QU). 
The overall mechanism of polymer material degradation might be divided into four stages, as follows:

i. Initiation of the degradation reaction with external stimuli, e.g., temperature, irradiation, with simultaneous chemical bonds' cleavage and formation of free alkyl radicals; ii. Initial propagation-reaction of alkyl radicals with oxygen and formation of peroxy/hydroxy radicals;

iii. Further propagation — chain branching and transferring radical activity to another chain;

iv. Termination and inactivated form creation with possible disproportionation reactions.

In general, polymer degradation leads to the shortening of the polymer chains' length and, therefore, it provides a material with different properties [32,64].

Thermal degradation starts while the interatomic vibration energy is equal to or exceeds the energy of interatomic bond dissociation. Then, the bond cleavage occurs and two active macroradicals, which may further take part in the propagation processes, are formed. In turn, UV light leads to the polymer chain photodegradation.

Similarly, it is initiated when the energy of absorbed radiation is greater than or at least equal to the dissociation energy of the individual bonds in the macromolecule. However, this type of degradation may also be initiated due to the presence of chromophore moieties which could shift their forms from basic singlet state to the excited singlet/triplet state, hence becoming incredibly reactive. In the case of PLA, the chromophore moieties are $\mathrm{C}=\mathrm{O}$ carbonyl moieties [32].

On the other hand, regarding the structure of ENR, $\mathrm{C}=\mathrm{C}$ bonds and unreacted oxirane rings are expected to be the most fragile to the free radicals' presence, thus being prone to oxidation or further crosslinking during aging. Another problem could be the presence of some proteins which may affect the material's resistance to elevated temperatures or UV irradiation $[65,66]$.

Additionally, the above-described degradation processes are the perfect examples of avalanche reactions as the propagation step provides various different free radical forms, e.g., oxygen-incorporated (hydroxy/peroxy) and alkyl radicals. Thus, once initiated, the degradation process is highly challenging to stop.

The plant-derived substances employed in this research, namely, $\delta$-tocopherol $(\delta-\mathrm{TF})$, curcumin $(\mathrm{CM}), \beta$-carotene $(\beta-\mathrm{CT})$, and quercetin $(\mathrm{QU})$, exhibit strong antioxidant properties, hence they are promising natural antioxidants for polymer-based materials. According to various studies presented in the literature, they may easily react with free radicals generated during the degradation of the polymer matrix, acting as free radical scavengers and simultaneously being oxidized [64,67-72].

In this way, the chemical compounds that promote ENR/PLA degradation are eliminated and the deterioration of the polymer matrix is prevented or delayed (only the natural additive is degrading at that time and not the polymer matrix itself) [64,67-69]. Some possible stabilization mechanisms are presented in the works performed by Choe et al. [64] ( $\delta-\mathrm{TF})$, Schneider et al. [67] (CM), Penicaud et al. [68] ( $\beta-\mathrm{CT})$, and Sokolova et al. [69] (QU). Some possible stabilization mechanisms, created on the basis of the available literature data presented in the works mentioned above, are given in Figure 8.

\section{Conclusions}

Taking into consideration the gathered data, some natural substances potentially able to stabilize elastic blends of epoxidized natural rubber (ENR) with poly(lactic acid) (PLA) have been found. Nonetheless, further analysis is highly advised. Among the tested natural additives, quercetin was proven to be a substance of the highest stabilizing potential. Thus, it can be applied while the material is subjected to elevated temperature or UV irradiation. The maximum shift of the aging coefficient detected for the QU-loaded sample is from 1 to $0.6 \pm 0.3$ for $200 \mathrm{~h}$-lasting UV aging and to $0.7 \pm 0.3$ for thermo-oxidative aging, which means a mechanical performance loss by only, respectively, $40 \%$ and $30 \%$. Moreover, curcumin seems to also be a quite efficient anti-aging additive for ENR/PLA blends while considering UV-resistance (the performance drop by approximately $50 \%$ ). Curcumin is 
also very promising as a future natural aging indicator. The hue angle of CM-filled samples might be shifted significantly from $(70 \pm 2)^{\circ}$ to $(58 \pm 2)^{\circ}$ for thermo-oxidative aging and up to $(63 \pm 2)^{\circ}$ for UV aging. Additionally, it was evidenced that these two substances, namely, quercetin and curcumin, do not lead to a deterioration of the mechanical performance of the ENR/PLA blends while added to the polymer matrix. The presented research indicates that the anti-aging effect in PLA-containing blends could be obtained with certain plant-derived additives. This provides new opportunities for the creation of the materials characterized by facilitated recycling and controllable lifespan.

Author Contributions: Conceptualization, formal analysis, data analysis, investigation, methodology, review and editing, A.M.; conceptualization, data analysis, investigation, methodology and writing, S.C. All authors have read and agreed to the published version of the manuscript.

Funding: Non-competition conceptual Ministry of Science and Higher Education project The best of the best! 4.0 implemented under the Priority Axis III of the Operational Program Knowledge Education Development 2014-2020 co-financed by the European Social Fund (application number for funding POWR.03.03.00-00-P019/18; contract with the Ministry of Science and Higher Education-No. MNiSW/2020/169/DIR/NN4 signed on 4 June 2020).

Institutional Review Board Statement: Not applicable.

Informed Consent Statement: Not applicable.

Data Availability Statement: No data available.

Acknowledgments: This work has been completed while the second author was the Lodz University of Technology, Poland.

Conflicts of Interest: The authors declare no conflict of interest.

\section{References}

1. Soroudi, A.; Jakubowicz, I. Recycling of bioplastics, their blends and biocomposites: A review. Eur. Polym. J. 2013, 49, 2839-2858. [CrossRef]

2. Andrzejewski, J.; Szostak, M.; Barczewski, M.; Łuczak, P. Cork-wood hybrid filler system for polypropylene and poly(lactic acid) based injection molded composites. Structure evaluation and mechanical performance. Compos. Part B Eng. 2019, 163, 655-668. [CrossRef]

3. Barczewski, M.; Sałasińska, K.; Szulc, J. Application of sunflower husk, hazelnut shell and walnut shell as waste agricultural fillers for epoxy-based composites: A study into mechanical behavior related to structural and rheological properties. Polym. Test. 2019, 75, 1-11. [CrossRef]

4. Aliotta, L.; Gigante, V.; Coltelli, M.B.; Cinelli, P.; Lazzeri, A. Evaluation of Mechanical and Interfacial Properties of Bio-Composites Based on Poly(Lactic Acid) with Natural Cellulose Fibers. Int. J. Mol. Sci. 2019, 20, 960. [CrossRef]

5. Rayung, M.; Ibrahim, N.A.; Zainuddin, N.; Saad, W.Z.; Razak, N.I.A.; Chieng, B.W. The Effect of Fiber Bleaching Treatment on the Properties of Poly(lactic acid)/Oil Palm Empty Fruit Bunch Fiber Composites. Int. J. Mol. Sci. 2014, 15, 14728-14742. [CrossRef] [PubMed]

6. Blessing, B.; Trout, C.; Morales, A.; Rybacki, K.; Love, S.A.; Lamoureux, G.; O’Malley, S.M.; Hu, X.; La Cruz, D.S.-D. The Impact of Composition and Morphology on Ionic Conductivity of Silk/Cellulose Bio-Composites Fabricated from Ionic Liquid and Varying Percentages of Coagulation Agents. Int. J. Mol. Sci. 2020, 21, 4695. [CrossRef]

7. KAIRYTĖ, A.; Kremensas, A.; Vaitkus, S.; Członka, S.; Strąkowska, A. Fire Suppression and Thermal Behavior of Biobased Rigid Polyurethane Foam Filled with Biomass Incineration Waste Ash. Polymers 2020, 12, 683. [CrossRef]

8. Członka, S.; Strąkowska, A. Rigid Polyurethane Foams Based on BioPolyol and Additionally Reinforced with Silanized and Acetylated Walnut Shells for the Synthesis of Environmentally Friendly Insulating Materials. Materials 2020, $13,3245$. [CrossRef] [PubMed]

9. Członka, S.; Kairytè, A.; Miedzińska, K.; Strakowska, A. Polyurethane Hybrid Composites Reinforced with Lavender Residue Functionalized with Kaolinite and Hydroxyapatite. Materials 2021, 14, 415. [CrossRef]

10. Bartos, A.; Anggono, J.; Farkas, Á.E.; Kun, D.; Soetaredjo, F.E.; Móczó, J.; Purwaningsih, H.; Pukánszky, B. Alkali treatment of lignocellulosic fibers extracted from sugarcane bagasse: Composition, structure, properties. Polym. Test. 2020, 88, 106549. [CrossRef]

11. Barczewski, M.; Mysiukiewicz, O.; Kloziński, A. Complex modification effect of linseed cake as an agricultural waste filler used in high density polyethylene composites. Iran. Polym. J. 2018, 27, 677-688. [CrossRef]

12. Szadkowski, B.; Kuśmierek, M.; Rybiński, P.; Żukowski, W.; Marzec, A. Application of Earth Pigments in Cycloolefin Copolymer: Protection against Combustion and Accelerated Aging in the Full Sunlight Spectrum. Materials 2020, 13, 3381. [CrossRef] [PubMed] 
13. Plota, A.; Masek, A. Lifetime Prediction Methods for Degradable Polymeric Materials—A Short Review. Materials $2020,13,4507$. [CrossRef]

14. Masek, A.; Cichosz, S.; Piotrowska, M. Biocomposites of Epoxidized Natural Rubber/Poly(lactic acid) Modified with Natural Fillers (Part I). Int. J. Mol. Sci. 2021, 22, 3150. [CrossRef]

15. Hamad, K.; Kaseem, M.; Ayyoob, M.; Joo, J.; Deri, F. Polylactic acid blends: The future of green, light and tough. Prog. Polym. Sci. 2018, 85, 83-127. [CrossRef]

16. La Mantia, F.P.; Botta, L.; Mistretta, M.C.; Di Fiore, A.; Titone, V. Recycling of a Biodegradable Polymer Blend. Polymers 2020, 12, 2297. [CrossRef]

17. Piemonte, V.; Gironi, F. Kinetics of Hydrolytic Degradation of PLA. J. Polym. Environ. 2013, 21, 313-318. [CrossRef]

18. Elsawy, M.A.; Kim, K.-H.; Park, J.-W.; Deep, A. Hydrolytic degradation of polylactic acid (PLA) and its composites. Renew. Sustain. Energy Rev. 2017, 79, 1346-1352. [CrossRef]

19. Najafi, N.; Heuzey, M.; Carreau, P.; Wood-Adams, P.M. Control of thermal degradation of polylactide (PLA)-clay nanocomposites using chain extenders. Polym. Degrad. Stab. 2012, 97, 554-565. [CrossRef]

20. Bijarimi, M.; Ahmad, S.; Rasid, R. Mechanical, thermal and morphological properties of poly(lactic acid)/epoxidized natural rubber blends. J. Elastomers Plast. 2012, 46, 338-354. [CrossRef]

21. Andrzejewski, J.; Skórczewska, K.; Kloziński, A. Improving the Toughness and Thermal Resistance of Polyoxymethylene/Poly(lactic acid) Blends: Evaluation of Structure-Properties Correlation for Reactive Processing. Polymers 2020, $12,307$. [CrossRef] [PubMed]

22. Formela, K.; Zedler, Ł.; Hejna, A.; Tercjak, A. Reactive extrusion of bio-based polymer blends and composites-Current trends and future developments. Express Polym. Lett. 2018, 12, 24-57. [CrossRef]

23. Yao, Q.; Cosme, J.G.; Xu, T.; Miszuk, J.M.; Picciani, P.H.; Fong, H.; Sun, H. Three dimensional electrospun PCL/PLA blend nanofibrous scaffolds with significantly improved stem cells osteogenic differentiation and cranial bone formation. Biomaterials 2017, 115, 115-127. [CrossRef]

24. Ahmed, M.F.; Li, Y.; Yao, Z.; Cao, K.; Zeng, C. TPU/PLA blend foams: Enhanced foamability, structural stability, and implications for shape memory foams. J. Appl. Polym. Sci. 2019, 136, 47416. [CrossRef]

25. Siracusa, V.; Karpova, S.; Olkhov, A.; Zhulkina, A.; Kosenko, R.; Iordanskii, A. Gas Transport Phenomena and Polymer Dynamics in PHB/PLA Blend Films as Potential Packaging Materials. Polymers 2020, 12, 647. [CrossRef] [PubMed]

26. Sookprasert, P.; Hinchiranan, N. Morphology, mechanical and thermal properties of poly(lactic acid) (PLA)/natural rubber (NR) blends compatibilized by NR-graft-PLA. J. Mater. Res. 2017, 32, 788-800. [CrossRef]

27. La Mantia, F.; Botta, L.; Morreale, M.; Scaffaro, R. Effect of small amounts of poly(lactic acid) on the recycling of poly(ethylene terephthalate) bottles. Polym. Degrad. Stab. 2011, 97, 21-24. [CrossRef]

28. Hamad, K.; Kaseem, M.; Deri, F. Effect of recycling on rheological and mechanical properties of poly(lactic acid)/polystyrene polymer blend. J. Mater. Sci. 2010, 46, 3013-3019. [CrossRef]

29. Li, S.; Leng, D.; Li, W.; Qie, L.; Dong, Z.; Cheng, Z.; Fan, Z. Recent progress in developing Li2S cathodes for Li-S batteries. Energy Storage Mater. 2020, 27, 279-296. [CrossRef]

30. Li, S.; Fan, Z. Encapsulation methods of sulfur particles for lithium-sulfur batteries: A review. Energy Storage Mater. 2021, 34, 107-127. [CrossRef]

31. Domínguez, R.; Barba, F.J.; Gómez, B.; Putnik, P.; Kovačević, D.B.; Pateiro, M.; Santos, E.M.; Lorenzo, J.M. Active packaging films with natural antioxidants to be used in meat industry: A review. Food Res. Int. 2018, 113, 93-101. [CrossRef] [PubMed]

32. Kirschweng, B.; Tátraaljai, D.; Földes, E.; Pukánszky, B. Natural antioxidants as stabilizers for polymers. Polym. Degrad. Stab. 2017, 145, 25-40. [CrossRef]

33. Sanches-Silva, A.; Costa, D.; Albuquerque, T.; Buonocore, G.G.; Ramos, F.; Castilho, M.C.; Machado, A.V.; Costa, H.S. Trends in the use of natural antioxidants in active food packaging: A review. Food Addit. Contam. Part A 2014, 31, 374-395. [CrossRef] [PubMed]

34. Goñi, M.L.; Gañan, N.; Strumia, M.C.; Martini, R.E. Eugenol-loaded LLDPE films with antioxidant activity by supercritical carbon dioxide impregnation. J. Supercrit. Fluids 2016, 111, 28-35. [CrossRef]

35. Doudin, K.; Al-Malaika, S.; Sheena, H.; Tverezovskiy, V.; Fowler, P. New genre of antioxidants from renewable natural resources: Synthesis and characterisation of rosemary plant-derived antioxidants and their performance in polyolefins. Polym. Degrad. Stab. 2016, 130, 126-134. [CrossRef]

36. Diouf-Lewis, A.; Commereuc, S.; Verney, V. Toward greener polyolefins: Antioxidant effect of phytic acid from cereal waste. Eur. Polym. J. 2017, 96, 190-199. [CrossRef]

37. Zhan, K.; Ejima, H.; Yoshie, N. Antioxidant and Adsorption Properties of Bioinspired Phenolic Polymers: A Comparative Study of Catechol and Gallol. ACS Sustain. Chem. Eng. 2016, 4, 3857-3863. [CrossRef]

38. Masek, A.; Latos-Brozio, M.; Kałużna-Czaplińska, J.; Rosiak, A.; Chrzescijanska, E. Antioxidant Properties of Green Coffee Extract. Forests 2020, 11, 557. [CrossRef]

39. Masek, A.; Latos-Brozio, M.; Chrzescijanska, E.; Podsedek, A. Polyphenolic Profile and Antioxidant Activity of Juglans regia L. Leaves and Husk Extracts. Forests 2019, 10, 988. [CrossRef]

40. Masek, A.; Chrzescijanska, E.; Latos-Brozio, M.; Zaborski, M. Characteristics of juglone (5-hydroxy-1,4,-naphthoquinone) using voltammetry and spectrophotometric methods. Food Chem. 2019, 301, 125279. [CrossRef] [PubMed] 
41. Masek, A.; Chrzescijanska, E.; Latos, M.; Zaborski, M. Influence of hydroxyl substitution on flavanone antioxidants properties. Food Chem. 2017, 215, 501-507. [CrossRef] [PubMed]

42. Olejnik, O.; Masek, A.; Kiersnowski, A. Thermal Analysis of Aliphatic Polyester Blends with Natural Antioxidants. Polymers 2020, 12, 74. [CrossRef] [PubMed]

43. Olejnik, O.; Masek, A. Bio-Based Packaging Materials Containing Substances Derived from Coffee and Tea Plants. Materials 2020, 13, 5719. [CrossRef] [PubMed]

44. Masek, A.; Plota, A. Influence of a Natural Plant Antioxidant on the Ageing Process of Ethylene-norbornene Copolymer (Topas). Int. J. Mol. Sci. 2021, 22, 4018. [CrossRef] [PubMed]

45. Masek, A.; Chrzescijanska, E.; Zaborski, M. Characteristics of curcumin using cyclic voltammetry, UV-vis, fluorescence and thermogravimetric analysis. Electrochim. Acta 2013, 107, 441-447. [CrossRef]

46. Masek, A.; Chrzescijanska, E.; Diakowska, K.; Zaborski, M. Application of $\beta$-carotene, a natural flavonoid dye, to polymeric materials as a natural antioxidant and determination of its characteristics using cyclic voltammetry and FTIR spectroscopy. Int. J. Electrochem. Sci. 2015, 10, 3372-3386.

47. Masek, A.; Latos, M.; Piotrowska, M.; Zaborski, M. The potential of quercetin as an effective natural antioxidant and indicator for packaging materials. Food Packag. Shelf Life 2018, 16, 51-58. [CrossRef]

48. Latos-Brozio, M.; Masek, A. The application of natural food colorants as indicator substances in intelligent biodegradable packaging materials. Food Chem. Toxicol. 2020, 135, 110975. [CrossRef]

49. Masek, A.; Zaborski, M.; Kosmalska, A.; Chrzescijanska, E. Eco-friendly elastomeric composites containing Sencha and Gun Powder green tea extracts. Comptes Rendus Chim. 2012, 15, 331-335. [CrossRef]

50. Liu, H.; Fang, Z.; Peng, M.; Shen, L.; Wang, Y. The effects of irradiation cross-linking on the thermal degradation and flameretardant properties of the HDPE/EVA/magnesium hydroxide composites. Radiat. Phys. Chem. 2009, 78, 922-926. [CrossRef]

51. Żołek-Tryznowska, Z.; Prica, M.; Pavlović, Ž.; Cveticanin, L.; Annusik, T. The influence of aging on surface free energy of corona treated packaging films. Polym. Test. 2020, 89, 106629. [CrossRef]

52. Homma, H.; Kuroyagi, T.; Mirley, C.L.; Ronzello, J.; Boggs, S.A. Diffusion of low molecular weight siloxane from bulk to surface [outdoor insulators]. In Proceedings of the Conference Record of the 1996 IEEE International Symposium on Electrical Insulation, Montreal, QC, Canada, 16-19 June 1996; Volume 1, pp. 279-282.

53. Atta, E.M.; Mohamed, N.H.; Abdel Gawad, A.A.M. Antioxidants: An Overview on the Natural and Synthetic Types. Eur. Chem. Bull. 2017, 6, 365-375. [CrossRef]

54. Seguchi, T.; Tamura, K.; Shimada, A.; Sugimoto, M.; Kudoh, H. Mechanism of antioxidant interaction on polymer oxidation by thermal and radiation ageing. Radiat. Phys. Chem. 2012, 81, 1747-1751. [CrossRef]

55. Wu, J.; Dong, J.; Wang, Y.; Gond, B.K. Thermal oxidation ageing effects on silicone rubber sealing performance. Polym. Degrad. Stab. 2017, 135, 43-53. [CrossRef]

56. Gardette, M.; Perthue, A.; Gardette, J.-L.; Janecska, T.; Földes, E.; Pukánszky, B.; Therias, S. Photo- and thermal-oxidation of polyethylene: Comparison of mechanisms and influence of unsaturation content. Polym. Degrad. Stab. 2013, 98, 2383-2390. [CrossRef]

57. Kakanuru, P.; Pochiraju, K. Moisture Ingress and Degradation of Additively Manufactured PLA, ABS and PLA/SiC Composite Parts. Addit. Manuf. 2020, 36, 101529. [CrossRef]

58. Bayart, M.; Gauvin, F.; Foruzanmehr, M.R.; Elkoun, S.; Robert, M. Mechanical and moisture absorption characterization of PLA composites reinforced with nano-coated flax fibers. Fibers Polym. 2017, 18, 1288-1295. [CrossRef]

59. Anetta, B.; Joanna, W. Innovations in the food packaging market-Intelligent packaging-A review. Czech J. Food Sci. 2017, 35, 1-6. [CrossRef]

60. Masek, A.; Zaborski, M. ENR/PCL Polymer biocomposites from renewable resources. Comptes Rendus Chim. 2014, 17, 944-951. [CrossRef]

61. Zeb, A.; Murkovic, M. Pro-Oxidant Effects of $\beta$-Carotene During Thermal Oxidation of Edible Oils. J. Am. Oil Chem. Soc. 2013, 90, 881-889. [CrossRef]

62. Ha, D.-O.; Park, C.U.; Kim, M.-J.; Lee, J. Antioxidant and prooxidant activities of $\beta$-carotene in accelerated autoxidation and photosensitized model systems. Food Sci. Biotechnol. 2012, 21, 607-611. [CrossRef]

63. Dintcheva, N.T.; Arrigo, R.; Baiamonte, M.; Rizzarelli, P.; Curcuruto, G. Concentration-dependent anti-/pro-oxidant activity of natural phenolic compounds in bio-polyesters. Polym. Degrad. Stab. 2017, 142, 21-28. [CrossRef]

64. Choe, E.; Min, D.B. Mechanisms of Antioxidants in the Oxidation of Foods. Compr. Rev. Food Sci. Food Saf. 2009, 8, 345-358. [CrossRef]

65. Yasin, S.; Hussain, M.; Zheng, Q.; Song, Y. Effects of ionic liquid on cellulosic nanofiller filled natural rubber bionanocomposites. J. Colloid Interface Sci. 2021, 591, 409-417. [CrossRef]

66. Rolere, S.; Liengprayoon, S.; Vaysse, L.; Sainte-Beuve, J.; Bonfils, F. Investigating natural rubber composition with Fourier Transform Infrared (FT-IR) spectroscopy: A rapid and non-destructive method to determine both protein and lipid contents simultaneously. Polym. Test. 2015, 43, 83-93. [CrossRef]

67. Schneider, C.; Gordon, O.N.; Edwards, R.L.; Luis, P.B. Degradation of Curcumin: From Mechanism to Biological Implications. J. Agric. Food Chem. 2015, 63, 7606-7614. [CrossRef]

68. Pénicaud, C.; Achir, N.; Dhuique-Mayer, C.; Dornier, M.; Bohuon, P. Degradation of $\beta$-carotene during fruit and vegetable processing or storage: Reaction mechanisms and kinetic aspects: A review. Fruits 2011, 66, 417-440. [CrossRef] 
69. Sokolová, R.; Ramešová, Š.; Degano, I.; Hromadová, M.; Gál, M.; Žabka, J. The oxidation of natural flavonoid quercetin. Chem. Commun. 2012, 48, 3433-3435. [CrossRef]

70. Abourashed, E.A. Bioavailability of Plant-Derived Antioxidants. Antioxidants 2013, 2, 309-325. [CrossRef]

71. Roleira, F.M.; Tavares-Da-Silva, E.J.; Varela, C.L.; Costa, S.C.; Silva, T.; Garrido, J.; Borges, F. Plant derived and dietary phenolic antioxidants: Anticancer properties. Food Chem. 2015, 183, 235-258. [CrossRef]

72. Hernández, I.; Alegre, L.; Van Breusegem, F.; Munné-Bosch, S. How relevant are flavonoids as antioxidants in plants? Trends Plant Sci. 2009, 14, 125-132. [CrossRef] [PubMed] 